\title{
Designing to heal; reconstructing communities after disasters
}

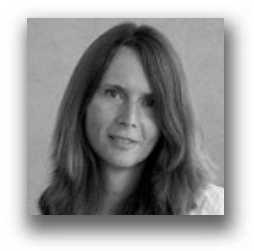

Jenny Donovan DipUD, MAUD, MPhil, MPIA

Principal, Inclusive Design, Albert Park, Victoria, Australia

Disasters, whether caused by nature or human nature are a major and growing issue. This paper explores the human and physical costs of disasters and suggests how planners and urban designers can help create the optimal conditions for people to put their lives back together and access, as far as possible, the opportunities they need to thrive and fulfil their potential. The paper draws on the author's observations from Kosovo, Sri Lanka and Northern Ireland. It concludes that whilst there is a rich vein of initiatives that directly or indirectly assist in the healing and rebuilding process they are unlikely to succeed without wider social, economic measures and political initiatives.

\section{Introduction}

Since 2000, the world has witnessed over 35 major conflicts and some 2,500 disasters (UNEP, 2012).

At any given time many people in many places are suffering from the aftermath of war or natural disasters, their communities fractured by death, dislocation and their familiar territory altered by the destruction of property and infrastructure. Creating the optimal conditions that enable these communities to overcome their trauma and rebuild their lives creates great challenges for built environment professionals.

This paper has been written to share some observations about the potential role of urban design to contribute to this healing process. It identifies how urban design can help to create the optimal circumstances for these communities to put their lives back together, come to terms with what has happened and have access to, as far as possible, the opportunities they need to get back on track, thrive and fulfil their potential.

The author has been fortunate enough to have worked on a number of reconstruction projects and/or studied urban design interventions in places as diverse as Kosovo, Northern Ireland and Sri Lanka. These experiences inform the views expressed in this article. These projects and the author's research into equitable urban design allow a few, tentative observations to be drawn about how urban design can help create the settings that can assist communities to rebuild and address their trauma, whether that trauma be of the flesh, emotional, or to their shared and valued surroundings. These observations are not put forward as the last word on the subject or even as firm conclusions.

The author's observations are not based on extensive research and are offered from a practitioner rather than an academic perspective. They are put forward to open a discussion about this important matter and to encourage planners, architects and engineers to think about how their work can help or hinder people to meet their needs. In particular, the paper addresses how built environments embody particular values and frame the choices open to people who share that environment; it also identifies what happens to communities when the built environment they share is irrevocably and involuntarily altered.

Please note it is not the intention in this paper to pass judgement on any particular side in these conflicts or to comment on what could have been done to avoid disasters. Nor is any attempt made in this paper to outline their history. The observations are written as an outsider and as a professional charged with the task of designing interventions that seek to allow people to get on with their lives and obtain more from their surroundings, irrespective of cultural identity or political ideology. It is recognised that the background to each conflict or natural disaster is hugely different and as such these observations are put forward with corresponding qualification.

\section{Urban design, people and place}

This paper is written from the perspective that an underlying characteristic of humanity is that humans are all fundamentally emotional beings, their understanding of the world filtered through the lens of their subjectivity (Porteous, 1990). Humans' cognitive reality, understanding of their surroundings and the opportunities it offers them is coloured by their preferences, values and experiences. This in turn informs any conclusions about whether that environment welcomes the individual and supports their wellbeing or makes them feel unwelcome and disadvantages them (Appleyard and Lintell, 1972). 
Urban Design and Planning

Volume 165 Issue DP2
Designing to heal;

reconstructing communities

after disasters

Donovan
Urban design, encompassing the net effect of the work of planners, architects, engineers, and so on, is a significant player in influencing these interpretations. The way these professionals design spaces and the quality of the environments they create give places characteristics that (often unintentionally) influence what people can do, where they can go and their conclusions about the choices open to them (Bentley et al., 2003; Krupat, 1985).

A place needs to be interpreted as safe and welcoming for people to feel able to use it and benefit from whatever opportunities it offers. In this respect, people's ability to meet their needs, access education, work, recreation, transport, health care, healthy food and social opportunities is a function of the way cities are designed.

Given the impacts of the work of urban designers, there is an ethical imperative to create the circumstances which give people the best possible chances to meet their needs and fulfil their potential. Urban environments can do this by providing opportunities that enable people to do what they need to do to support their wellbeing, develop their skills, forge social bonds and live lives congruent to their principles. Failing to provide these opportunities, either deliberately or accidentally in pursuit of say, a particular economic or political agenda, risks fundamentally compromising the quality of people's lives. Therefore, to paraphrase the Social Exclusion Unit in the UK, this paper is written from the perspective that no one should be disadvantaged by their surroundings (adapted from Social Exclusion Unit (2001)).

\section{The fundamental problem}

At one level a conflict or a natural disaster destroys buildings and spaces; it may remodel the topography or sterilise productive land. At another level it profoundly, and often suddenly, changes the meaning a place has to the people that occupy it. The previous meanings and associations are wiped clean and are overlaid with new ones, typically negative and associated with loss and destruction (Borrell, 2011). A place which may have matured to be rich in qualities that contributed greatly to the wellbeing of the resident community typically becomes used by a single land use or no land use. For example the foreshore in Hambantota, Sri Lanka which was once home to fishermen, guest houses, shops and streets was stripped of its utility to the community by the 2004 Boxing Day tsunami. The people who lived there, the emotional capital they invested in the place and the infrastructure they used to support themselves and meet their needs were all destroyed. The place became a scarred landscape of foundation stones, cleared sites, remnant trees and rubble, rarely visited and overlaid with associations of sadness and loss. Likewise the conflict in Kosovo (1989-1990) has left a legacy of buildings and spaces isolated behind barbed wire for years, useless to

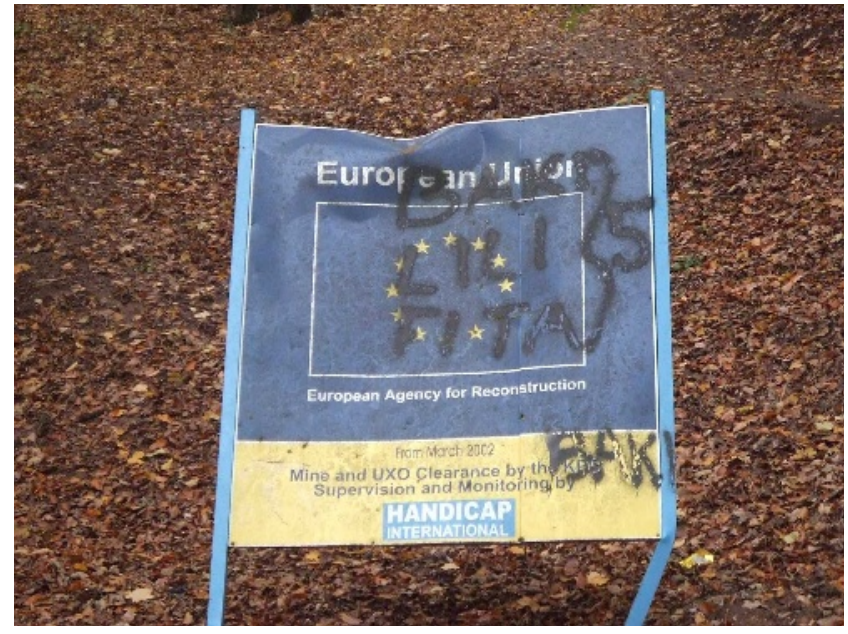

Figure 1. The legacy of unexploded ordnance (photograph by the author)

anyone because of the risk of unexploded ordnance. The official mine clearing programme lasted 3 years to clear the bulk of the mines 1999-2002 (Scott, 2002) but during the author's visits in 2007 and 2008 there were still newspaper reports of people who had been hurt or killed stepping on forgotten landmines. This has had the effect of slowing down the rebuilding process and reopening psychological wounds that keep the conflict 'live'. The author frequently came across signs that served to remind people of the extent of the land effected (Figure 1).

The quality of many people's lives in these situations is compromised directly by shock, fear, injury and bereavement, a sense of powerlessness and frustration at their limited ability to help themselves or for outside agencies to help (Borrell, 2011). Indirectly the loss of livelihoods, disruption of infrastructure, loss of skills, dislocation and the burden of refugees on host communities may also be a problem (UNEP and the United Nations Centre for Human Settlements, 1999). Depending on the disaster, some communities also suffer further from shame, communal violence and hate, lack of a sense of closure and the legacy of contamination (Earthwatch, see earthwatch. unep.ch/emergingissues/humanset/kosovo.php).

The ability of these communities to address these problems and meet their needs is further diminished by the destruction of the social and economic infrastructure that the community relies on and the attendant loss of potential for individuals within those communities to meet their own needs.

\section{Rebuild the same, or rebuild better?}

A typical dimension of the problem is the rapid evolution of priorities. Immediately after the event there is a need to meet 
emergency needs (shelter, food, water, medical care, etc.); later there is a need to replace infrastructure and rebuild more permanently. At each stage there is the risk of precluding beneficial options later on by well-meant but inappropriate interventions.

Considering these questions is the very heart of planning; however, this process takes time, which may seem incompatible with the considerable and understandable desire to rebuild as quickly as possible. Therefore the challenge is to balance a quick response with the best response. After initial emergency needs have been met, the question is should time be taken to replan an area and address strategic long-term issues such as sustainability, or should as prompt a response as possible be facilitated, retaining existing property boundaries and planning regimes and potentially 'locking in' existing problems that could potentially have been overcome (Figure 2). This was also demonstrated recently in the aftermath of the bushfires in Victoria and South Australia, where the requirement for planning permission for rebuilding damaged or destroyed houses - with the attendant contemporary sustainability standards, and so on - was seen by many as a bureaucratic hindrance to people who had already suffered enough (Powell, 2009).

\section{Communal appropriation of public space}

A characteristic of the destruction brought about by disaster and conflict is that the values embodied in the rebuilt environment reflect the values of the people in charge. The world is full of places that possess qualities or characteristics that mean some of their potential occupants are made to feel less welcome in that space than others. These places are not always consciously designed to discriminate, but often end up

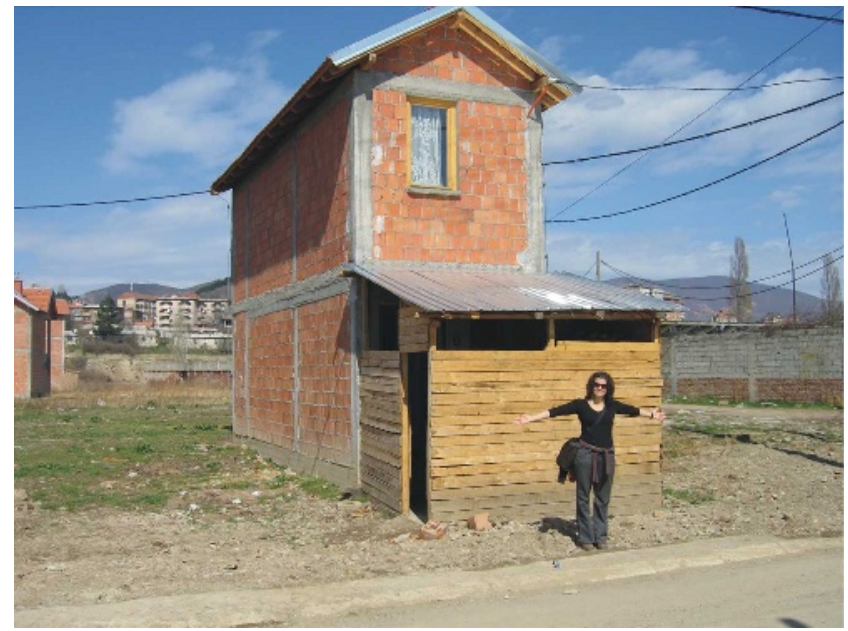

Figure 2. Reconciling pre-existing property boundaries with modern housing expectations may present difficulties (photograph by the author) allocating environmental welfare to one section of the community rather than another.

At its most subtle, this creates a feeling that a person is a visitor in someone else's space. This is a sense familiar to most people who have ever ventured down a private street or into a private courtyard and feel the curtains twitching. At the other extreme is the destruction of neighbourhoods or the installation of walls, legal and psychological barriers that deny some people the ability to access particular spaces that are important to them and that they used to be able to access.

Within this spectrum lie interventions like the installation of murals that are distressing to some members of the community but highly valued by others, such as adorn many a gable wall in Northern Ireland, the installation of war memorials or the naming of parks and streets to commemorate victories - and therefore defeats for other people - and the destruction of cultural icons and their replacement with others. This technique was used in Kosovo where the Serbian nationalists who controlled the former province constructed many Serbian orthodox churches in this predominantly Islamic country, usually on key sites and often on top of pre-existing icons. They also destroyed many 'kullas' (Guttman, 1999), the fortified farmhouse/clan headquarters that are characteristic of the Kosovan countryside (Figure 3) and the traditional hub of community life. In Kosovo the pendulum has now swung the other way and one of the results of this frequent naming and renaming means that street and park names are poorly recognised in the wider community, making activities like ordering and directing taxis particularly challenging.

The systematic imposition of different cultural values was in full swing at the time of the uprising that ultimately led to the United Nations (UN) sponsored ceasefire, withdrawal of Serbian troops and the Serbian government, and ultimately the recent

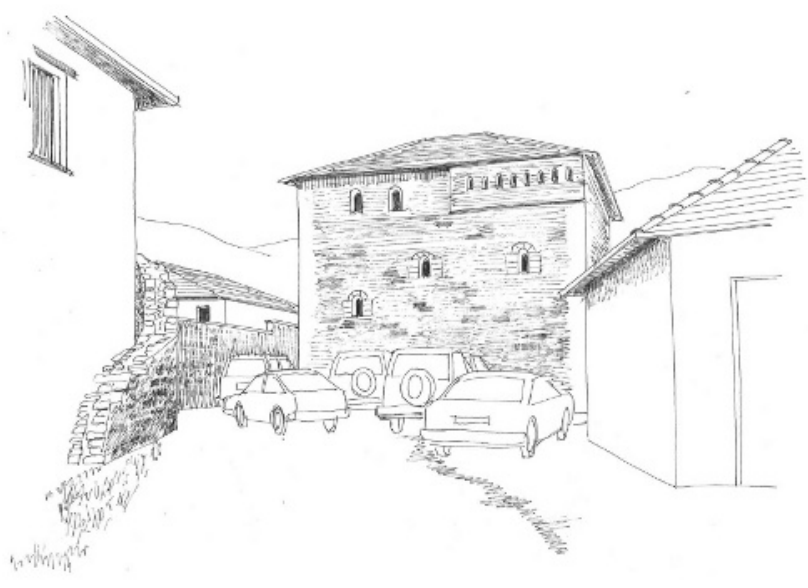

Figure 3. Reconstructed kulla (sketch by the author) 
Designing to heal;

reconstructing communities

after disasters

Donovan

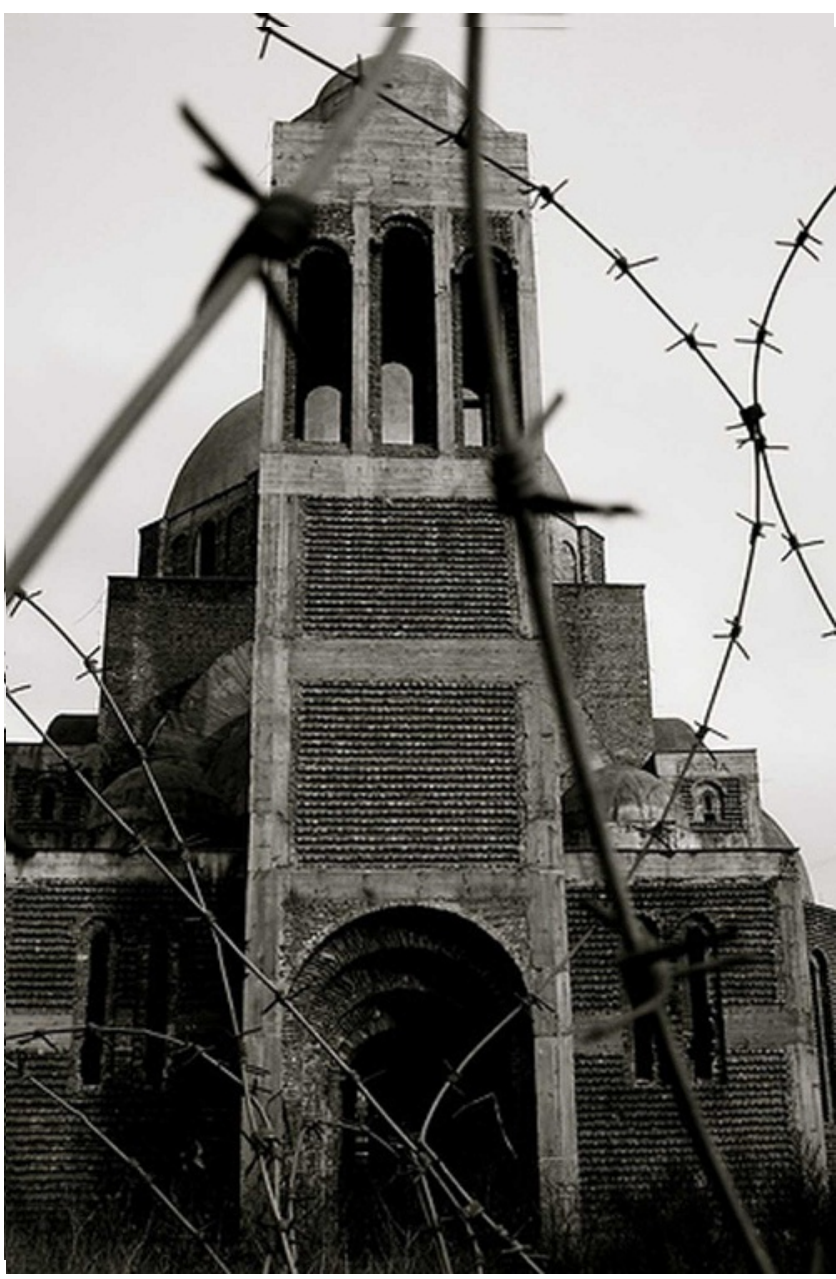

Figure 4. Serbian orthodox church in Pristina, commissioned as part of a programme of Serbianising Kosovo, abandoned before it could be finished (photograph reproduced by kind permission of Helmut Alexander Oelkers)

declaration of independence. This has meant that many key spaces in Kosovan cities have half-built orthodox churches, work abandoned with the change of administration (Figure 4) and a countryside that is littered with partially demolished kullas. This state-sponsored imposition of one culture over another took place at the same time that many Serbian and Albanian (the cultural identity of most Kosovans) militias burnt down churches or mosques, laid mines within them and/or daubed offensive graffiti on them (Guttman, 1999). The widespread and coordinated terror from both sides, of which this was just a small part, has contributed to an almost complete polarisation of society, with the Kosovar Albanians occupying most of the country and isolated pockets of Serbians mainly in the north following the displacement of up to one million people (Jansen, 2008). Many members of both communities tell harrowing stories of being displaced from their homes and communities, sometimes several times over, and harbour a profound sense of loss and fear that it may happen again.

\section{Responses to conflict and disaster}

The balance of this paper explores some design responses to the issues identified above. Some of these responses relate solely to natural disasters, some to conflicts/manmade disasters and some are applicable to both.

\subsection{Defend against reoccurrences without precluding beneficial interventions}

Perhaps the most pressing and obvious response to disaster is to minimise the risk of reoccurrence. Because of this unpredictability or incomplete understanding of natural systems it is beyond the scope of this paper to comment on what might technically be the best response to specific disasters; however, whatever the responses are, they should be done in a way that does not preclude future positive actions.

Immediately after a disaster, emotions tend to be running high and the responses are often correspondingly pronounced. Last year Australia witnessed an emotional debate about responses to the terrible bushfires of February 2009 (McGeough, 2009). Opinions varied from taking action to remove all the trees anywhere near anyone in bushfire-prone areas, to removing the houses. In Sri Lanka a buffer zone was created around the coast, within which development was not allowed. Initially that zone was several hundred metres deep. This was later reduced and amended to respond to local conditions such as coastal vegetation and topography. If all the trees were to be knocked down in bushfire-prone areas in Australia and all land blighted near the coast of Sri Lanka, a relatively small and crowded country, then perhaps the cure could prove to be worse than the ailment.

Likewise where conflict resolution is attempted through the hardening of barriers, such as the peace wall that runs through part of Belfast and the barricades in parts of Kosovo, care needs to be taken to keep lines of communication open to allow for eventual reconciliation. This objective underpinned the reconstruction of the old bridge in Mostar after the Bosnian conflict in the mid-1990s, which was identified as 'a symbol of reconciliation, international co-operation and of the coexistence of diverse cultural, ethnic and religious communities' (Unesco, 2011).

Similarly the new bridge in Metrovica/Metrovice, Kosovo was built by the French contingent of the Nato Kosovo force (KFOR) after the war to facilitate connections and symbolise progress towards peace between the otherwise polarised Serbian and Albanian communities (Figure 5). 
Urban Design and Planning

Volume 165 Issue DP2
Designing to heal;

reconstructing communities

after disasters

Donovan

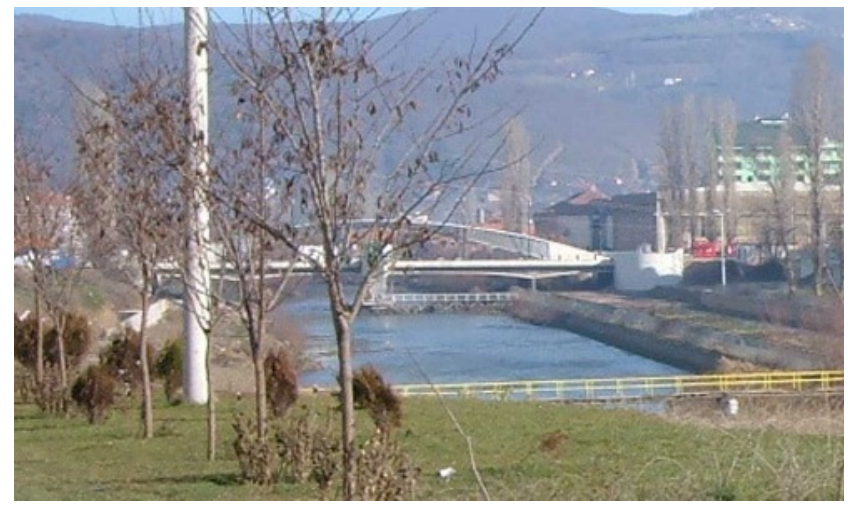

Figure 5. Metrovica/Metrovice Bridge (uploaded from http:// flickr.com/photo/23442653@N00/3939079733 using 'Flickr upload bot')

\subsection{Understand the social landscape}

Places have meaning for people, associations and memories (Porteous, 1977). Understanding the uses, values, aspirations and fears that people have about different areas is an essential part of rebuilding a place sensitively. While it is never entirely possible to 'see a place through their eyes', the time and effort taken to understand what is important to the effected community will be essential to informing appropriate solutions and making best use of what are invariably scarce resources. Ideally this information should be gathered beforehand, for if it is compiled afterwards it will be inevitably altered by the disaster. Whenever it is assessed, understanding the 'social landscape' can provide an important tool for setting priorities and nuancing an evolving design.

\subsection{Respond to and predict evolving priorities}

As identified above, the imperative to act quickly can diminish the ability to act well. However, allocating resources to predict future needs and getting 'runs on the board' by flagship developments can provide an important psychological boost for the community and can help to address frustration. Examples of this would be the construction of the new market building/public hall in Hambantota in Sri Lanka on land wiped clean by the Boxing Day tsunami, or the bridge built in Metrovica/Metrovice.

\subsection{Address appropriation}

Disasters, natural or manmade, often result in one community losing more than another, resulting in anger and frustration and the hardening of divisions, which were often pre-existing. The techniques described in the following subsections are useful lines of exploration to address this conflict and provide people with the chance to enjoy the same opportunities and qualities and create the common ground that at least makes positive interaction possible. By themselves these techniques may not solve appropriation but at least they may play a role in ensuring the way we design built environments do not compound it.

\subsubsection{Respect cultural values}

In Kosovo, religious buildings often provided a focus of community life and for this reason were often targeted in the conflict. The UN force charged with administering Kosovo, the UN Mission in Kosovo (UNMIK), and the Nato peace-keeping forces, KFOR, made a commitment to protecting the cultural icons of Kosovo and repairing the more architecturally, historically and socially important damaged ones. They have done this with the help of several international non-government organisations, such as Cultural Heritage without Borders (http://www.chwb.org/kosovo/english/home.htm). Together they have achieved varied success, which is not surprising given the tensions in the land and competing claims on their resources. Nonetheless, most cities retain at least some buildings and spaces which represent the community that has been displaced from that city. Unfortunately, this commitment has only been achieved at the expense of creating different barriers - many of the protected churches, monasteries and mosques are isolated behind walls, barbed wire and sand bags, visited only by their UN or Nato guards, their congregation for the most part long departed or dead.

Despite this, these iconic buildings help to create an environment within which reconciliation is possible by providing a

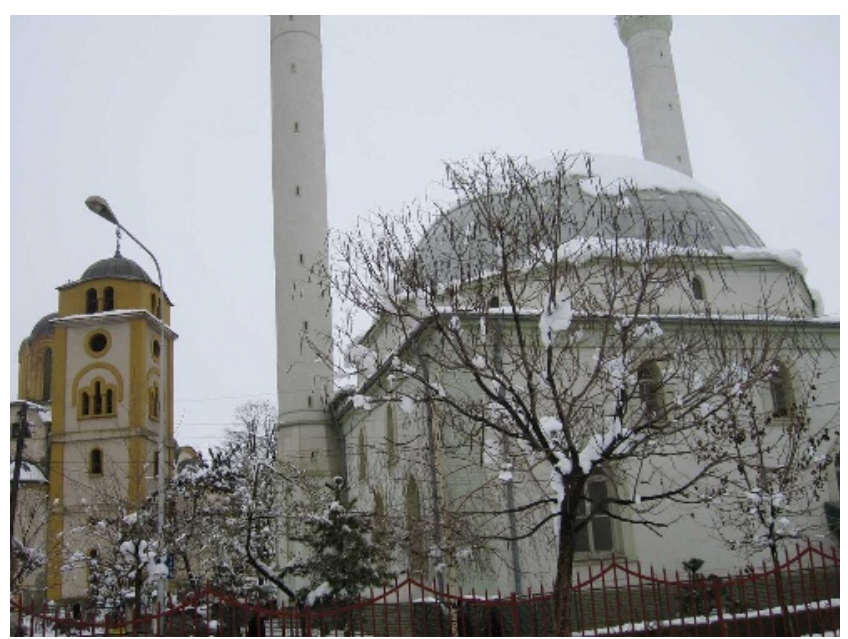

Figure 6. The mosque and church adjacent to one another in Ferizaj, Kosovo, now an overwhelmingly Muslim community. The church is protected by UN peacekeepers and a barbed wire fence (photograph by the author) 
Urban Design and Planning

Volume 165 Issue DP2
Designing to heal;

reconstructing communities

after disasters

Donovan reminder of Kosovo's relatively recent multicultural past. The architectural co-existence of church and mosque and their continued and significant contribution to many an urban skyline (Figure 6) help to foster a sense that the divisions in Kosovan society are not permanent. Should, or hopefully when, the displaced people feel it is safe to return home, they will at least have an existing and recognisable hub for their community and a link to their past.

\subsubsection{Create new meaning}

In a city like Belfast with a legacy of many areas being strongly Republican or Unionist, overlaid with Catholic and Protestant religious affiliation respectively, the city centre has always been neutral ground and a place that offered both communities opportunities to interact. With the economic boom that Northern Ireland has until recently enjoyed, the city centre has been expanding towards the city's docklands, with major developments such as the titanic quarter on the site of the historic Harland and Wolff shipyards (http://www.titanicquarter.com/) designated in the 2005 Belfast metropolitan plan. This expansion has provided the opportunity to create new icons for the city that alter the way people think about their city and change it from being a place thought of as divided and war-torn to a modern, confident city in which religious and political affiliation are a source of identity but not conflict.

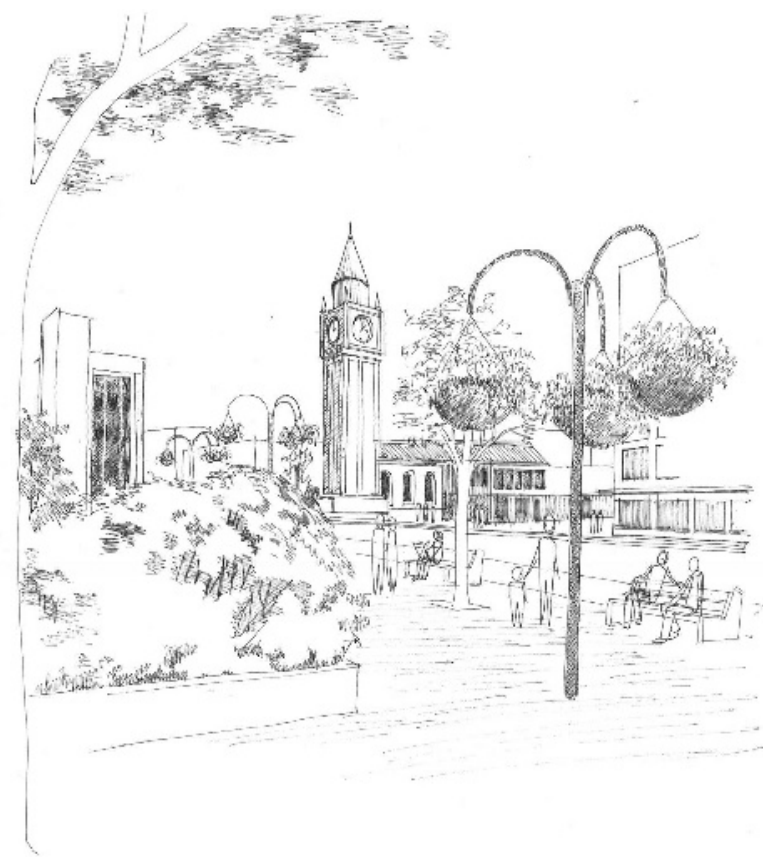

Figure 7. The Albert Memorial, Belfast (sketch by the author)

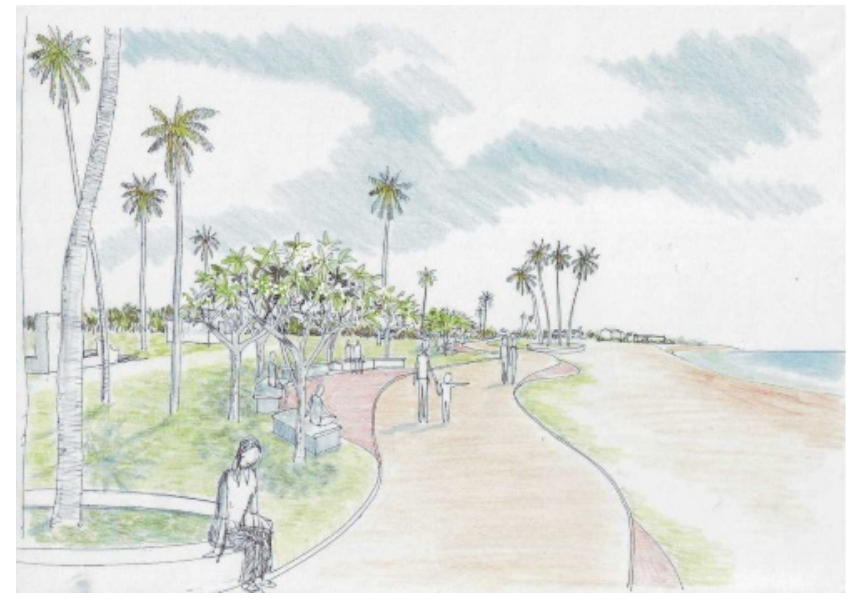

Figure 8. Hambantota Beach Park (sketch by the author)

The creation of this sectarian neutral identity and renewed civic pride has been demonstrated by the redevelopment of the area around the Albert Memorial (Figure 7) and the docklands themselves, which have become a second social heart for the city. These spaces contain artworks that were devised to be happy and joyful, presenting a positive, politically neutral and hence inclusive view of the city.

Echoes of this approach have also been attempted in Kosovo where many of the cities have renamed streets that previously celebrated Serbian nationalist heroes or events with names such as Nene Tereza (mother Theresa), after the late Albanian nun. By celebrating a catholic nun and humanitarian rather than a Kosovan nationalist, the symbolism of the street becomes inclusive rather than sectarian.

In Hambantota the abandoned foreshore is being redeveloped as a park (Figure 8) after careful consultation with the local community to understand how the park might be designed to provide the uses and attractions that are relevant to the community. By drawing people to the foreshore and providing settings for new recreational and economic opportunities that resonate with the community it is hoped that the area can again contribute to people's quality of life, albeit in a different way than before.

\subsubsection{Create new neutral alignments}

In Northern Ireland a further strand in the political efforts to overlay sectarian divisions with mutually binding allegiances has been to re-brand Belfast and the cities of Kosovo as European cities, sidestepping the divisive competing national identities. In both these cities where the symbolism of flags is so important, it is interesting to see the prevalence of the blue European flags and the evolution in social habits evidenced by 


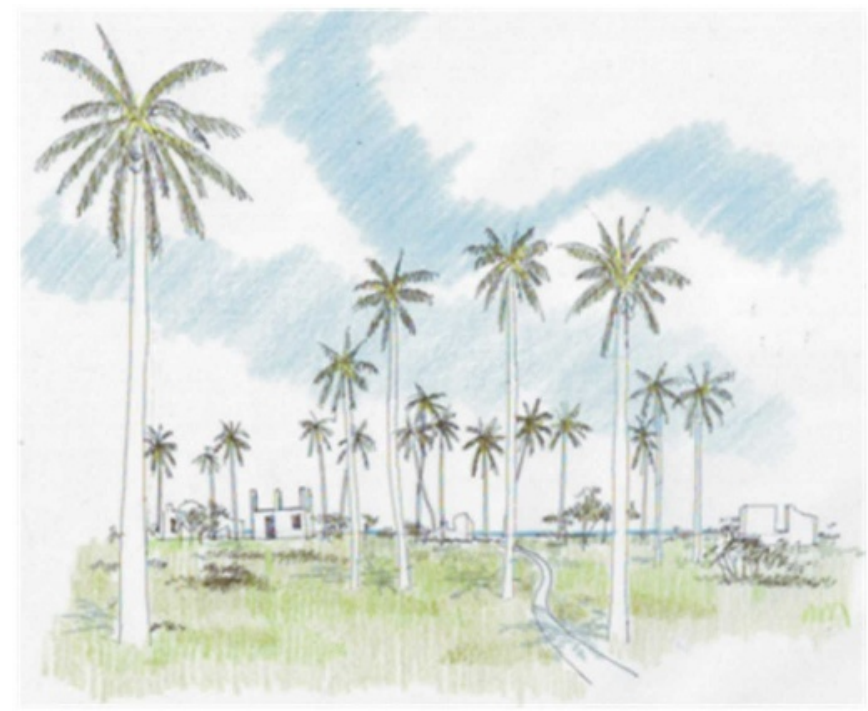

(a)

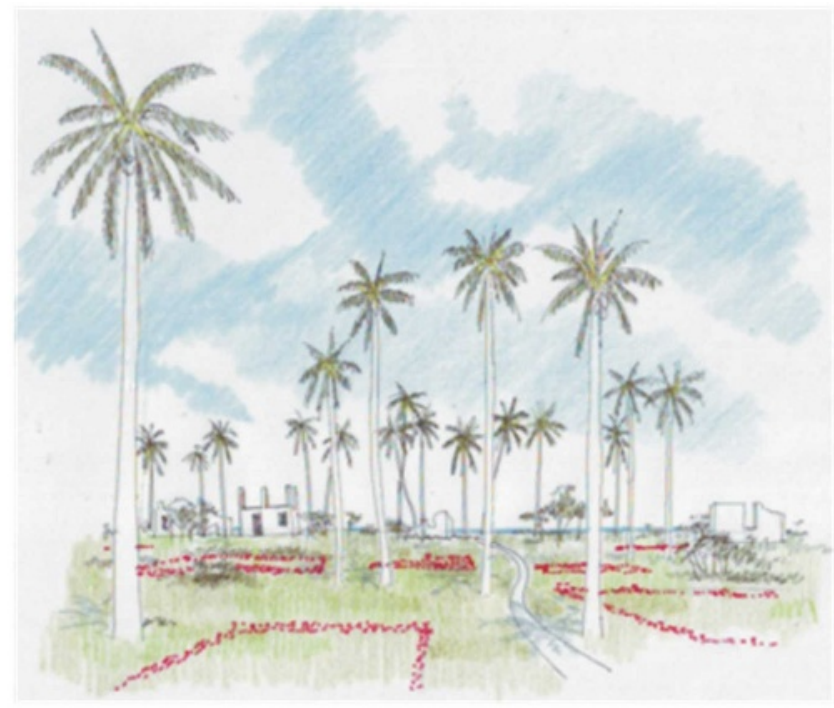

(b)

Figure 9. Hambantota Beach Memorial Park: (a) typical view for most of the year and (b) view in late December (sketches by the author)

the opening of more and more cafes, usually untainted by sectarian allegiance, and a commitment to outdoor socialising despite the challenges of the climate.

\subsubsection{Change the paradigm}

Northern Ireland has long been aware of the contribution that tourism can make to a country's economy, looking south to the republic's success in attracting tourists who rarely ever ventured over the border. However, the peace that has taken hold in the last 10 years has seen a rapid rise in tourists, attracted by the province's immense natural beauty and buzz of its pubs and cafes. With this has come a sense that the economic contribution the tourists bring is dependent on the peace, creating a sense that 'we have to be on our best behaviour' according to Stephen Watson, planner with the Northern Ireland Planning Service (interview, November 2009).

\subsubsection{Respectfully remember the past}

It should not be forgotten that many people suffered in the conflicts in Ireland, Sri Lanka and Kosovo. The present author cannot of course say with absolute certainty that the following is true, but suspects there were many acts of great humanity, sacrifice and heroism, as well as many crimes committed by all sides. Efforts made to remember the events of the past and explain them to future generations without glorifying them are likely components of reconciliation. In the author's eyes this means a change from war memorials that mark territory for a particular side in a conflict to ones that communicate the suffering and sacrifice of both sides and the events that led up to it. Northern Ireland and to a lesser extent Kosovo have made great strides in this direction through the dedication of peace gardens such as the St Patrick's Peace Garden in Downpatrick, Co. Down.

Reconciliation should not require the complete loss of character of a community. To this end a recent debate in Northern Ireland explored whether some historically significant political wall murals should be listed for state protection because of their historic significance. A further initiative of the Northern Irish government has been to put these local skills to good effect and fund the creation of politically neutral murals, enlivening what would otherwise be blank walls and contributing to the city's identity (Reimaging Communities (Arts Council of Northern Ireland, 2007)).

A further aspect of reconciliation is to cast conflict as a thing of the past, no longer characteristic of the place but adding interest. This is witnessed through the many black taxi tours in Belfast that take people to see the murals of the past conflict and visit sites made famous (or infamous) by atrocities. The Europa Hotel is proudly known by all in Belfast as the most bombed hotel in Europe. 
Urban Design and Planning

Volume 165 Issue DP2
Designing to heal;

reconstructing communities

after disasters

Donovan
In Sri Lanka a feature of the tsunami was its sudden and cataclysmic arrival on Boxing Day 2004. As part of a commission to design a park on the foreshore that commemorated the event in a way that was relevant to the local culture, the author worked with the community to come up with the concept described below that reflected the association with a particular time of year (Figure 9).

The concept envisages that in places where buildings were completely devastated by the tsunami, the outlines of the buildings are planted with flowering plants that bloom in late December. This will serve to remind people both of the anniversary and the impact of the tsunami, as well as creating a strong, simple visual composition that can provide an iconic image for the park and for Hambantota.

\subsection{Putting planning and urban design in perspective}

While planning and urban design may play a part in helping create the environmental conditions within which reconciliation and reconstruction can flourish, it seems unlikely that it can kick start the process alone. In other words it may be a catalyst but not the cause of reconciliation and reconstruction. In Belfast's case the momentum for reconciliation arose from a politically arranged ceasefire and the economic boom that followed. To a large extent planners did not set the agenda for reconciliation but sought to foster changes that were already emerging. In the words of Stephen Watson they 'woke up one day and asked what happened' (interview, November 2009). Having made that point, the genie of sectarianism is not yet completely in the bottle and it should be remembered that 'peace walls' dividing particular communities are now more numerous than at any other time.

In Sri Lanka's case the recent ending of the war and the warmth of its people will hopefully pay dividends for a community that richly deserves something to go right for them. The investment this may bring will be essential in allowing them to benefit from all the careful planning that has been done as part of the reconstruction process.

In Kosovo the declaration of independence and with it the clarification of its status has brought renewed hope and confidence in the emerging country and a sense that people are free to look beyond their past. Hopefully, this continues and Kosovo will emerge as a stronger economy and tourist destination, capitalising on the scenery of its surrounding mountains, the charm of some of its provincial cities and the warmth and resourcefulness of its people. Against such a backdrop of peace and investment, planning and urban design may make a contribution to facilitating reconciliation and realise as social benefits the costs of protecting the cultural resources of the presently displaced cultures. The themes covered in this paper are explored in greater depth in the book Designing to Heal published by CSIRO and available from September 2012.

\section{REFERENCES}

Appleyard D and Lintell M (1972) The environment quality of city streets: the residents viewpoint. Journal of the American Institute of Planners 38: 84-101

Arts Council of Northern Ireland (2007) Reimaging Communities. See http://www.artscouncil-ni.org/news/2007/new10072007. htm (accessed 11/10/2011).

Bentley I, Alcock A, Murrain P, McGlynn S and Smith G (2003) Responsive Environments. Architectural Press, London, UK.

Borrell J (2011) Rupture, loss, identity and place following the 2009 Victorian bushfires: a theoretical exploration. New Community Quarterly 9(2): 14-22.

Guttman C (2000) Kosovo: burned books and blasted shrines. Interview with András Riedlmayer. UNESCO Courier September.

Jansen GR (2008) Albanians and Serbs in Kosovo: An Abbreviated History. Colorado State University, Fort Collins, Colorado, first written 25 April 1999; updated 22 July 2008.

Krupat E (1985) People in Cities: The Urban Environment and Its Effects. Cambridge University Press, Cambridge, UK.

McGeough P (2009) The painful truth. Sydney Morning Herald, 14 February.

Northern Ireland Environment Agency (2011) Case Study 3 Titanic Quarter. See www.ni-environment.gov.uk/ niea_conservation_case_study3_titanic_quarter-2.pdf (accessed 10/10/2011).

Porteous JD (1977) Environment and Behaviour. AddisonWesley.

Porteous JD (1990) Landscapes of the Mind: Worlds of Sense and Metaphor. University of Toronto Press, Toronto, Canada.

Powell A (2009) Rebuilding after the bushfires. Sydney Morning Herald 11 February.

Scott JJ (2002) The Kosovo Mine Action Co-ordination Centre: The most successful mine action program ever. Journal of Mine Action, April, Issue 6.1, see http://maic.jmu.edu/ JOURNAL/6.1/focus/scott/scott.htm (accessed 10/10/ 2011).

Social Exclusion Unit, Department of the Deputy Prime Minister (UK) (2001) National Strategy Action Plan - A New Commitment to Neighbourhood Renewal. Her Majesty's Stationery Office (HMSO), London. 
UNEP (United Nations Environment Programme) (2012) Fact Sheet for Disasters and Conflicts United Nations Environment Programme. See http://www.unep.org/pdf/ UNEP_Profile/Disasters_and_conflicts.pdf (accessed 04/ 04/2012).

UNEP and the United Nations Centre for Human Settlements
(1999) The Kosovo Conflict: Consequences for the Environment and Human Settlements. See http:// postconflict.unep.ch/publications/finalreport.pdf (accessed 04/04/2012).

UNESCO (2011) World Heritage Register. See http://whc.unesco. org/en/list/946 (accessed 10/10/2011).

\section{WHAT DO YOU THINK?}

To discuss this paper, please email up to 500 words to the editor at journals@ice.org.uk. Your contribution will be forwarded to the author(s) for a reply and, if considered appropriate by the editorial panel, will be published as discussion in a future issue of the journal.

Proceedings journals rely entirely on contributions sent in by civil engineering professionals, academics and students. Papers should be 2000-5000 words long (briefing papers should be 1000-2000 words long), with adequate illustrations and references. You can submit your paper online via www.icevirtuallibrary.com/content/journals, where you will also find detailed author guidelines. 